\title{
ESTAÇÃO CIÊNCIA - CONSTRUINDO PERSPECTIVAS PARA O PROCESSO DE ENSINO E APRENDIZAGEM DA MATEMÁTICA
}

\author{
Renata Camacho Bezerra ${ }^{1}$ \\ Marli Schmitt ${ }^{2}$ \\ Danielli Aquino Somensari ${ }^{3}$
}

\section{RESUMO}

$\mathrm{O}$ artigo que ora apresentamos reflete, no âmbito da universidade, a articulação que vem se realizando entre o ensino, a pesquisa e a extensão no projeto intitulado "Estação Ciência: Módulo de Matemática”, numa parceria entre a Universidade Estadual do Oeste do Paraná UNIOESTE Campus de Foz do Iguaçu e a Fundação Parque Tecnológico ITAIPU FPTI/BR. As atividades desenvolvidas ao longo do projeto, relacionam conceitos matemáticos presentes no cotidiano das pessoas, de forma prazerosa, dinâmica e criativa, explorando o lúdico, incentivando a curiosidade e ainda, construindo e (re) construindo o conhecimento, tanto dos alunos quanto dos atuais e futuros professores da disciplina de Matemática. O projeto realiza-se desde o ano de 2006, sendo que a partir de 2008 passou a ter caráter permanente.

Palavras-chave: Extensão. Lúdico. Matemática.

\footnotetext{
1 Mestre em Educação Matemática. Professora da Universidade Estadual do Oeste do Paraná - UNIOESTE Campus de Foz do Iguaçu. Membro do Grupo de Pesquisa em Matemática e Educação Matemática. E-mail: renatacamachobezerra@gmail.com.

2 Professora de Matemática. Docente Colaboradora da Universidade Estadual do Oeste do Paraná - UNIOESTE - Campus de Foz do Iguaçu. Ex-bolsista PTI/PDTA/C\&T. E-mail: marlischmitt@hotmail.com.

3 Acadêmica do Curso de Licenciatura em Matemática da Universidade Estadual do Oeste do Paraná UNIOESTE - Campus de Foz do Iguaçu. Ex-bolsista do PTI/PDTA/C\&T. E-mail: danielisomensari@hotmail.com.
} 


\title{
STATION SCIENCE - CONSTRUCTING PERSPECTIVE FOR THE EDUCATION PROCESS AND LEARNING OF THE MATHEMATICS
}

\begin{abstract}
The article that however we present reflects in the scope of the university the joint carried through among education, the research and the extension in the entitled project "Station Science: Module of Mathematics", in a partnership enters the State University of the West of the Paraná - UNIOESTE Campus of Foz do Iguaçu and the Foundation Technological Park ITAIPU - FPTI/BR. The activities developed throughout the project, relate mathematical concepts gifts in the daily one of the people, of pleasant, dynamic form and creative, exploring the playful one, stimulating the curiosity and still, constructing e (reverse speed) constructing the knowledge, as much of the pupils how much of the current and future professors of it disciplines of Mathematics. The project became permanent since the year of 2006 being that from 2008 it started to have permanent character.
\end{abstract}

Keywords: Extension. Entertaiment. Mathematics.

\section{INTRODUÇÃO}

Quando falamos em Matemática, percebemos diversas reações, normalmente não favoráveis à disciplina. Isso ocorre devido a vários fatores, dentre eles está a forma como ela é ensinada e o fato de muitos acreditarem que não possuem aptidão para aprendê-la.

A sociedade, de forma geral, acredita ou considera que a Matemática é algo difícil e abstrato, pronto e acabado. Também acredita ou considera que somente os dotados de tal aptidão é que podem compreendê-la, gostar dela e tirar excelentes notas. Recebendo assim, o título de inteligentes.

Antes de tudo, sejamos estritos. Se dizemos "arauto", dizemos "o que anuncia" algo que já exista. Pois assim é: o monstro está nos anunciando que algo já aconteceu. Não há como existir o que não é possível. Assim, quando o monstro aparece à nossa frente, é porque ele já era possível. (LINS, 2004, p.107) 
A Matemática, muitas vezes, é vista como um "monstro", consequência do medo já existente, antes mesmo de conhecê-la, geralmente por influência de outras pessoas. Segundo a Revista Diversa da Universidade Federal de Minas Gerais (2003, [não paginado]), "a Matemática foi tradicionalmente inserida na lista dos mais terríveis monstros do Ensino Fundamental, Médio e, não raramente, também no Superior”.

Essa visão pode passar de geração em geração, quando, por exemplo, os pais acreditam que a disciplina seja difícil e promovem essa ideia, induzindo seus filhos a pensarem da mesma maneira. Isso pode gerar neles uma grande aversão à Matemática antes mesmo de entrar na escola.

No âmbito escolar, isso pode ocorrer principalmente no $1^{\circ}$ e $2^{\circ}$ Ciclos do Ensino Fundamental, quando as aulas são ministradas por um único professor para todas as disciplinas, pelo motivo de o professor não possuir uma formação específica em Matemática. Os alunos acabam acreditando que a Matemática é difícil, exata, pronta e acabada, sem vínculo com o dia a dia. Sendo que já possuem a concepção de que esta disciplina está relacionada apenas com números, e nada mais.

Em pesquisa realizada com crianças do Ensino Fundamental, da $3^{\circ}$ série da Escola Municipal Ademar Marques Curvo, localizada na Vila São Sebastião, em Foz do Iguaçu, durante as atividades desenvolvidas na Estação Ciência, mais de 80\% delas disseram gostar de Matemática, pois, segundo elas, é durante essas aulas que existe maior interação entre os alunos. No entanto, $100 \%$ deles acreditam que a Matemática se resume apenas a contas e números.

Estes alunos possuem uma concepção Pitagórica do que seja a Matemática, pois de acordo com Baraldi (1999, p. 84) "para os Pitagóricos, todas as coisas eram números". A Matemática explicava a ordenação do Universo, tirava do caos e trazia à ordem, fazendo a natureza se render ao seu princípio: os números.

Para eles, a Matemática não está presente em nossas ações, como, por exemplo, atravessar a rua com menor distância ou a percepção da distância do carro e sua velocidade até o ponto em que ela se encontra, ou ainda não conseguem relacionar objetos presentes no dia a dia, como os encontrados no caminho de casa à escola, com formas geométricas. Segundo os alunos entrevistados, eles só utilizam a Matemática na sala de aula, não a veem fora da escola, e quando a veem é somente em casa, para estudar. 
Isso vem ao encontro das ideias de Meira \& da Rocha Falcão (1994, p. 39), que afirmam que "a matemática da escola diz respeito àquelas atividades que se passam em um contexto bastante específico, a sala de aula de matemática na escola”.

Por meio de conversas informais e de nossas experiências, percebemos que, na maioria das vezes, as aulas de matemática são pouco diversificadas pelos professores e, ainda, por mais que eles saibam da importância do material manipulável nas aulas de matemática, não notamos, na maioria das vezes, o envolvimento destes professores na utilização ou produção do seu próprio material.

Diante desse quadro, é necessário que pensemos alternativas metodológicas, através de ações efetivas, entre a universidade e a comunidade (Educação Básica), que resultem numa reversão do panorama atual para o desenvolvimento do pensamento em sala de aula, seja em Matemática, ou em outras disciplinas. Em Matemática, acredita-se que a causa da maioria dos problemas ocorre quando não se estimula o intelecto matemático, ou ainda, dificulta-lhe a aprendizagem com uma metodologia de ensino incoerente e distante da realidade do aluno.

Tal como Vasconcelos (2002, [não paginado]), percebemos que se faz necessário, desde as Séries Iniciais, a construção desse pensamento, pois "é nesta fase da vida que ele se desenvolve, juntamente com o conhecimento e o raciocínio". O desenvolvimento do ser humano exige mais que um simples aprendizado, necessita da construção do pensamento, de raciocínio e de criação.

Pensando em contribuir com o processo de ensino e aprendizagem da Matemática é que aceitamos o desafio de fazer parte da "Estação Ciência" e idealizamos o "Módulo de Matemática", numa parceria entre a Universidade Estadual do Oeste do Paraná - UNIOESTE Campus de Foz do Iguaçu, por meio do Curso de Licenciatura em Matemática, e a Fundação Parque Tecnológico ITAIPU - FPTI/BR, por meio do Programa de Ciência e Tecnologia (C\&T).

\section{MATERIAL E MÉTODOS}

A Estação Ciência está situada no Parque Tecnológico de Itaipu - PTI e tem por objetivo atender alunos da rede pública e privada de ensino do município e da região, inclusive Paraguai e Argentina, levando conhecimento científico a todos eles. Existem quatro 
módulos na Estação Ciência, sendo eles: o Módulo de Biologia, de Física, de Informática e de Matemática.

No Módulo de Matemática, temos por objetivo divulgar e popularizar a Matemática como uma ciência resultante de uma construção social, dinâmica e em constante evolução. As atividades desenvolvidas têm por objetivo mostrar os conceitos matemáticos presentes no cotidiano de cada um de nós através de exposições, experimentos interativos e lúdicos.

É uma oportunidade para aproximarmos o universo científico do dia a dia, para instigar a curiosidade e difundir conhecimentos.

Em suma, o trabalho realizado por este módulo pretende facilitar o processo de ensino e aprendizagem da Matemática através de atividades lúdicas e prazerosas, com alunos do Ensino Fundamental, e posteriormente estender ao Ensino Médio.

As atividades desenvolvidas são criadas, recriadas e, às vezes, apenas adaptadas, mas sempre têm como foco principal, aspectos lúdicos e que permitam que o aluno vivencie, experimente e comprove que a Matemática é uma ciência dinâmica, criativa, resultante de uma construção coletiva, realizada ao longo dos séculos.

Dessa forma, esperamos que as atividades desenvolvidas permitam que alunos e professores construam e (re)construam seus conhecimentos matemáticos através das atividades realizadas.

Procuramos através do Módulo de Matemática, ao longo do trabalho atingir os seguintes objetivos: tornar o conhecimento Matemático acessível a todos; possibilitar intercâmbio de saberes entre a universidade e a comunidade; produzir e divulgar conhecimento científico; estimular a curiosidade e o espírito científico dos alunos do ensino fundamental e também dos professores e futuros professores de Matemática; oportunizar a construção do conhecimento matemático fora do ambiente escolar; estabelecer relações interdisciplinares entre a Matemática e outras ciências; estabelecer relações transdisciplinares entre a Matemática e outras ciências; articular ensino, pesquisa e extensão através de atividades matemáticas; desenvolver o raciocínio lógico e a criatividade de alunos e futuros professores de Matemática; Valorizar o aspecto lúdico no ensino da Matemática; Facilitar o processo de ensino e aprendizagem da Matemática; Articular a Matemática escolar e a Matemática do dia-a-dia; permitir que alunos do Ensino Fundamental e Médio e futuros professores de Matemática vivenciem uma Matemática dinâmica e criativa; aproximar Universidade e Comunidade; socializar o conhecimento Matemático em todos os níveis de ensino e despertar no aluno o interesse pela Matemática. 


\title{
3 RESULTADOS E ANÁLISE
}

A seguir faremos um relato de duas atividades, dentre as realizadas no Módulo de Matemática, nos últimos meses, mostrando não somente o trabalho desenvolvido, mas refletindo sobre ele de forma a nortear atividades futuras.

\subsection{JOGOS BOOLE}

A lógica é fundamental a todas as ciências, e importante para o nosso desenvolvimento, inclusive para o nosso dia a dia, portanto preparar e capacitar o aluno para o futuro é uma necessidade.

\begin{abstract}
O matemático britânico George Boole (1815-1864), foi o inspirador dos Jogos Boole. Seus estudos de Álgebra que é um ramo da Matemática relacionado á lógica do verdadeiro (1) e falso (0) e que se constitui na base teórica a partir da qual é estruturado o computador, à pesquisa de Inteligência Artificial e a ligação efetuada pelos telefones, entre muitas outras atividades. (MELLO, 2003, p. 15)
\end{abstract}

A lei especial da Lógica de Boole, de acordo com Mello (2003), nos diz que $x=1$ ou $\mathrm{x}=0$, ou seja, utilizamos o sistema Binário.

Os estudos de Boole serviram de inspiração para o professor de Matemática Procópio Mendonça de Mello e a Professora de idiomas Dora Anita de Mello, criar os Jogos Boole.

O Professor Procópio Mendonça Mello desenvolveu este trabalho a partir de seus estudos em lógica, preocupado em oferecer uma Matemática em sala de aula dinâmica, lúdica e atraente, despertando o interesse dos alunos para a disciplina, estimulando-os a pesquisa e incentivando-os a curiosidade.

Ainda segundo Mello (2003, p. 3), "este jogo consiste em utilizar histórias lógicas, permitindo o desenvolvimento do raciocínio e a formação do pensamento". O intuito é despertar o interesse pela Matemática trabalhando de forma lúdica e prática por meio de enigmas e desafios.

Acreditamos que mais importante ou tão importante quanto à aprendizagem do aluno é a capacidade que ele terá de utilizar este aprendizado que obteve no seu diaa-dia. [...] É importante auxiliar a criança a passar, progressivamente, do pensamento concreto à utilização de outras formas de pensamento. Preparar e capacitar o aluno para o futuro é uma necessidade. (MELLO, 2003, p. 5) 
Com este jogo podemos trabalhar não só a Matemática, mas também outras disciplinas, como português, história, geografia, biologia, entre outras, tanto quanto se queira, dependendo da necessidade e criatividade do professor, desde a Educação Infantil até o Ensino Médio. Mesmo que se trabalhem diversos conteúdos em diferentes disciplinas ele sempre vai estar ligado à lógica, que é um ramo da Matemática, pois o objetivo principal deste jogo é desenvolver o raciocínio lógico.

Por isso tornam-se mais interessantes do que os problemas padrão, aguçando a curiosidade e permitindo que ele desenvolva sua criatividade, sua iniciativa e seu espírito explorador.

Os desafios são contados por histórias indicando o caminho para o desenvolvimento e conclusão do raciocínio, uma valiosa opção para se trabalhar com crianças é utilizar material atraente e colorido, de forma a estimular o aluno.

A seguir iremos exemplificar uma história que trabalhou o tema cadeia alimentar (Biologia e Matemática), utilizada no desenvolvimento da atividade.

Cartas necessárias: homem, gavião, jacaré, peixe, capivara, cobra, cidade, floresta e brejo.

Conta-se a história: O jacaré se alimenta de cobra; A capivara vive na floresta; O peixe é uma das presas do homem; A cobra vive no brejo.

Diante disso, provocamos a reflexão e conseqüentemente o desenvolvimento do conceito lógico dos alunos através das seguintes perguntas: Quem vive na cidade? Qual é o alimento do gavião?

\section{2 ÁGUA E VOLUME}

A atividade com o tema água ocorreu na semana do dia 22 de março, quando o mundo celebra o dia mundial da água, com o intuito de despertar no aluno o interesse e a responsabilidade pelo tema.

A Usina Hidrelétrica de Itaipu Binacional sediou o evento Nacional do dia da água no Parque Tecnológico de Itaipu, que recebeu o nome "Movimento em Defesa da Água: SOS $\mathrm{H} 2 \mathrm{O}$ ".

De acordo com o jornal Gazeta do Povo (17/04/2007) "o tema para a celebração do dia mundial da água realizado na Usina de Itaipu foi proposto pela ONU - Organização das 
Nações Unidas", reunindo representes das mais diversas instituições, brasileiras, da iniciativa privada, governos e a comunidade em geral. Durante o evento houve a assinatura da carta "Pacto da Água", tendo como objetivo o compromisso de todos os participantes de promover o uso correto da água do Planeta junto à sociedade. Após assinada esta carta foi entregue a Ministra de Meio Ambiente, Marina da Silva, para que o governo federal também assumisse o compromisso de elaborar e fiscalizar ações de preservação.

Apesar do Brasil possuir 12\% de reservatório de água doce do mundo ainda assim é possível o desabastecimento, devido à contaminação dos rios e por não possuir o devido tratamento e preservação das nascentes.

A Usina de Itaipu faz a sua parte na questão da preservação, pois ela é a responsável por $74,6 \%$ de geração de energia elétrica consumida no Brasil, sendo a água sua matéria prima, sem ela não haveria energia gerada pela usina.

Esta atividade teve como propósito principal, ater e mobilizar os alunos para a importância de preservação da água e seu uso, ou seja, trabalhar a conscientização ambiental e a matemática.

Antes de iniciá-la, tivemos com os alunos um diálogo sobre a importância da água, formas de uso, desperdício e aproveitamento, conscientizando-os e mobilizando-os a pensarem e analisarem a maneira como estão vivendo e consumindo a água.

O objetivo da atividade consistiu em trabalhar o conceito de volume utilizando a água como instrumento, além de materiais recicláveis.

Para realizá-la cada aluno recebeu uma garrafa pet com água de cores diferentes, um recipiente, dois copos milimetrados, papel e lápis. Os alunos deveriam encher os recipientes até a marca indicada para descobrir a capacidade máxima de volume e anotá-lo, já que todos possuíam medidas diferentes. Para isto tinham o auxílio de dois copos milimetrados, um com capacidade de $180 \mathrm{ml}$ (mililitros) e outro de $50 \mathrm{ml}$.

Nesta atividade trabalhamos o conceito de volume (Matemática) e questões da atualidade (preservação da Água) e vale salientar que tal conceito embora esteja presente no dia-a-dia só é formalizado pela Matemática na $5^{\text {a }}$ série, embora na atividade tenhamos trabalhado com crianças do primeiro e segundo ciclos do Ensino Fundamental. 


\section{CONSIDERAÇÕES FINAIS}

O projeto atende todas as escolas da rede municipal de Foz do Iguaçu, dos municípios lindeiros e dos paises vizinhos (Argentina e Paraguai), além de toda a comunidade. As visitas são agendadas pela própria Estação Ciência.

Para a realização das atividades os alunos são divididos em três grupos permanecendo em cada módulo por cerca de 20 minutos, participando das atividades.

Para estes alunos o fato de saírem da sala de aula é algo totalmente diferente, eles estão em um local voltado à educação, porém diferente da sala de aula, não tem quadro, giz, uma carteira atrás da outra, e estão em contato com aquilo que vivenciam no dia-a-dia.

No Módulo de Matemática pudemos observar as seguintes reações nas crianças:

a) no início não relacionaram o Módulo com a Matemática;

b) relacionaram os Jogos Boole com Biologia, pois este trabalhava o conteúdo "Cadeia Alimentar" e acreditavam ser este um jogo ou uma brincadeira de adivinhações e não um trabalho de Matemática;

c) em relação ao experimento com a água eles acreditavam que também estavam trabalhando no Módulo de Biologia, pois relacionaram a água, os materiais recicláveis a este módulo e não à Matemática.

A atividade da água foi a que obtivemos maior empolgação por parte dos alunos, pois eles puderam vivenciar e realizar a atividade, sozinhos. Construíram o seu conhecimento através da experiência, através do contato direto com o material, deixando de serem "sentistas" para serem cientistas.

Em suma, percebemos que as atividades produzidas neste módulo puderam contribuir para o desenvolvimento do aluno e despertar o seu interesse pela Matemática, aguçando sua curiosidade, tirando a visão que este possui de que a disciplina é difícil, monótona e sem vínculo com a realidade.

Com esse trabalho acreditamos estar contribuindo para o processo de ensino e aprendizagem da Matemática, interagindo com outras Ciências, desmistificando-a, tornando-a acessível a todos, através de atividades lúdicas, dinâmicas e diversificadas. Mudando a idéia de que ela é somente contas e números, vista e aprendida somente na sala de aula e nada mais, mostrando a todos que está presente em nossas ações do dia-a-dia, até mesmo nas mais elementares. 
E foi através de um projeto de caráter extensionista que pudemos ao longo dos dias, vivenciarmos a indissociabilidade entre o ensino, a pesquisa e a extensão. Sendo que os dados apresentados são parciais e que o projeto ora apresentado continua em desenvolvimento.

\section{AGRADECIMENTOS}

Agradecemos a FPTI/BR por fomentar as atividades desenvolvidas através de bolsas de extensão aos acadêmicos que participam do projeto e do fornecimento dos materiais necessários ao desenvolvimento das atividades.

\section{REFERÊNCIAS}

BARALDI, Ivete Maria. As Concepções Matemáticas e Suas Influências no Ensino. IN: BARALDI, Ivete Maria. Matemática na Escola: Que Ciência é esta? Bauru: EDUSC, 1999.

COELHO, Elaine Cristina Basqueroto; RAIMUNDO, Cleusa Iracema Pereira. (Org.) Modelo de artigo de relato de experiência extensionista. Extensio: Revista Eletrônica de Extensão, Florianópolis, v. 6, n.7, jul. 2009. Disponível em: http://www.periodicos.ufsc.br/index.php/extensio . Acesso em: 10 jul. 2009.

DIVERSA, Revista da Universidade Federal de Minas Gerais - UFMG, 2003. http://www.ufmg.br/diversa/3/matematica.htm., Ano 1 - no. 3 - Edição Vestibular.

FALCÃO, Jorge Tarcísio da Rocha; MEIRA, Luciano. A Experiência Matemática na Escola de $1^{\circ}$ Grau. Vol. 2, Nº. 2. São Paulo: Educação Matemática em Revista, 1994. 93p.

FALCÃO, Jorge Tarcísio da Rocha. A Psicologia da Educação Matemática no Contexto da Psicologia. IN: FALCÃO, Jorge Tarcísio da Rocha. Psicologia da Educação Matemática. São Paulo: Editora Autêntica, 2003. 248 p. 
LINS, Rômulo Campos. Matemática, Monstros, Significados e Educação Matemática. In.: BICUDO, Maria Aparecida Viggiani; BORBA, Marcelo de Carvalho. (Orgs.). Educação Matemática: Pesquisa em Movimento. São Paulo: Cortez, 2004. 317 p.

MELLO, Procópio Mendonça. Jogos Boole: A Maneira Divertida de Ficar Inteligente. Porto Alegre: Webeditora, 2003. 51 p.

VASCONCELOS, Marcelo C. Um Estudo Sobre o Incentivo e Desenvolvimento do raciocínio Lógico dos Alunos, Através da Estratégia de Resolução de Problemas. Florianópolis/SC, 2002. (www.teses.eps.ufsc.br/defesa)

http://canais.ondarpc.com.br/gazetadopovo/imprensa/controle (acessado em 17/04/2007). 